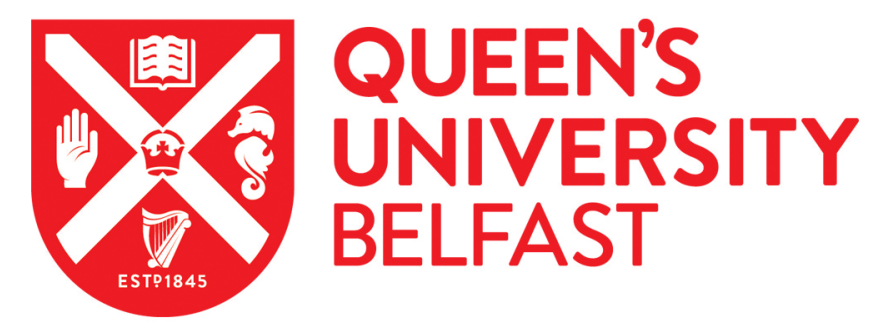

\title{
UWB Antenna with Dynamically Reconfigurable Notch-Band using Rectenna and Active Booster
}

Quddious, A., Abbasi, M. A. B., Tahir, F. A., Antoniades, M. A., Vryonides, P., \& Nikolaou, S. (2019). UWB Antenna with Dynamically Reconfigurable Notch-Band using Rectenna and Active Booster. IET Microwaves, Antennas and Propagation, 13(12), 2046 - 2052. https://doi.org/10.1049/iet-map.2018.5664

\section{Published in:}

IET Microwaves, Antennas and Propagation

\section{Document Version:}

Peer reviewed version

Queen's University Belfast - Research Portal:

Link to publication record in Queen's University Belfast Research Portal

Publisher rights

(c) The Institution of Engineering and Technology 2019. This work is made available online in accordance with the publisher's policies. Please refer to any applicable terms of use of the publisher.

\section{General rights}

Copyright for the publications made accessible via the Queen's University Belfast Research Portal is retained by the author(s) and / or other copyright owners and it is a condition of accessing these publications that users recognise and abide by the legal requirements associated with these rights.

Take down policy

The Research Portal is Queen's institutional repository that provides access to Queen's research output. Every effort has been made to ensure that content in the Research Portal does not infringe any person's rights, or applicable UK laws. If you discover content in the Research Portal that you believe breaches copyright or violates any law, please contact openaccess@qub.ac.uk. 


\title{
UWB Antenna with Dynamically Reconfigurable Notch-Band using Rectenna and Active Booster
}

\author{
Abdul Quddious ${ }^{1 *}$, Muhammad Ali Babar Abbasi ${ }^{1}$, Farooq A. Tahir ${ }^{2}$, M.A. Antoniades ${ }^{3}$, Photos \\ Vryonides ${ }^{1}$ and Symeon Nikolaou ${ }^{1}$ \\ ${ }^{1}$ Department of Electrical Engineering, Frederick University, 7, Y. Frederickou Str. Pallouriotisa, Nicosia, Cyprus \\ ${ }^{2}$ Research Institute for Microwave and Millimeter-Wave Studies (RIMMS), National University of Sciences \& \\ Technology (NUST), Sector H-12, Islamabad, Pakistan \\ ${ }^{3}$ Department of Electrical and Computer Engineering, University of Cyprus, 1 Panepistimiou Avenue 2109 \\ Aglantzia, Nicosia, Cyprus \\ *12mseeaquddious@seecs.edu.pk
}

\begin{abstract}
In this paper a UWB monopole antenna with a dynamically reconfigurable notch-band, along with the associated RF-triggered power management unit (PMU) that enables the dynamic reconfigurability, are presented. The UWB monopole antenna has a rectangular slot which hosts a J-shaped stub, electrically connected with the radiator using one PIN diode switch. When the diode is OFF, the monopole antenna has a UWB characteristic, while when it is turned ON a frequency notch is created at $5.6 \mathrm{GHz}$. The diode is fed from a PMU that consists of a rectenna and a DC-to-DC active booster. When the rectenna that consists of a patch antenna and a rectifier receives a $-11 \mathrm{dBm}$ or higher $5.6 \mathrm{GHz}$ signal, it rectifies the RF signal into a sufficiently high DC voltage. The rectified DC voltage is applied to the cascaded DC-to-DC booster as enabling signal, and the booster provides at its output terminal sufficient DC power to actuate the PIN diode and thus dynamically reconfigure the UWB antenna. The dynamically reconfigurable notch-band is created immediately in response to the reception of an external, $-11 \mathrm{dBm}$ RF signal at $5.6 \mathrm{GHz}$, and it disappears in real time immediately after the external RF signal is removed.
\end{abstract}

\section{Introduction}

Ultra-wideband (UWB) devices are widely used in wireless sensor networks, healthcare and biomedical wireless systems, and in-house devices in radar detecting, locating, and communications [1]. Presently, the increasing numbers of narrow band applications that share part of the UWB spectrum are causing heavy congestion in the UWB spectrum causing interference and degrading the systems' performance [2]. These applications include $3.6 \mathrm{GHz}$ IEEE $802.11 \mathrm{y}$ Wireless Local Area Networks (WLAN) (3.6575-3.69 GHz), $4.9 \mathrm{GHz}$ public safety WLAN $(4.94-4.99 \mathrm{GHz})$ and $5 \mathrm{GHz}$ IEEE $802.11 \mathrm{a} / \mathrm{h} / \mathrm{j} / \mathrm{n}$ WLAN $(5.15-5.35 \mathrm{GHz}, 5.25-5.35 \mathrm{GHz}$, 5.47-5.725 GHz, 5.725-5.825 GHz) and they all operate within the FCC UWB band of 3.1-10.6 GHz. To overcome this problem, agile radios are required that make use of smart reconfigurable UWB antennas capable of cancelling single-, dual- or multi- band interference [3-9]. There are several methods to achieve a band-notched UWB antenna. U-shaped slots, L-shaped slots [5], or capacitive-loaded loops (CLL) [6, 7] can be added either on the radiating element or on the RF ground plane. Alternatively, $\lambda / 4$ open stubs or $\lambda / 2$ parasitic linear segments can be added following the approach used in [3-6].

To achieve the band-notch reconfigurability, electrical switches are used to connect and disconnect antenna parts in order to redistribute the antenna surface currents. Many designs have used PIN diodes $[7,10]$ to switch between "ON"/"OFF" states, or varactors [3] using continuously tunable voltage elements. Alternatively, radio-frequency micro-electromechanical systems (RF-MEMS) [5] have been used to reconfigure antenna characteristics. Comparing PIN diodes and RF-MEMS someone should consider that the switching time of RF-MEMS is in the range of $1-200 \mu \mathrm{sec}$
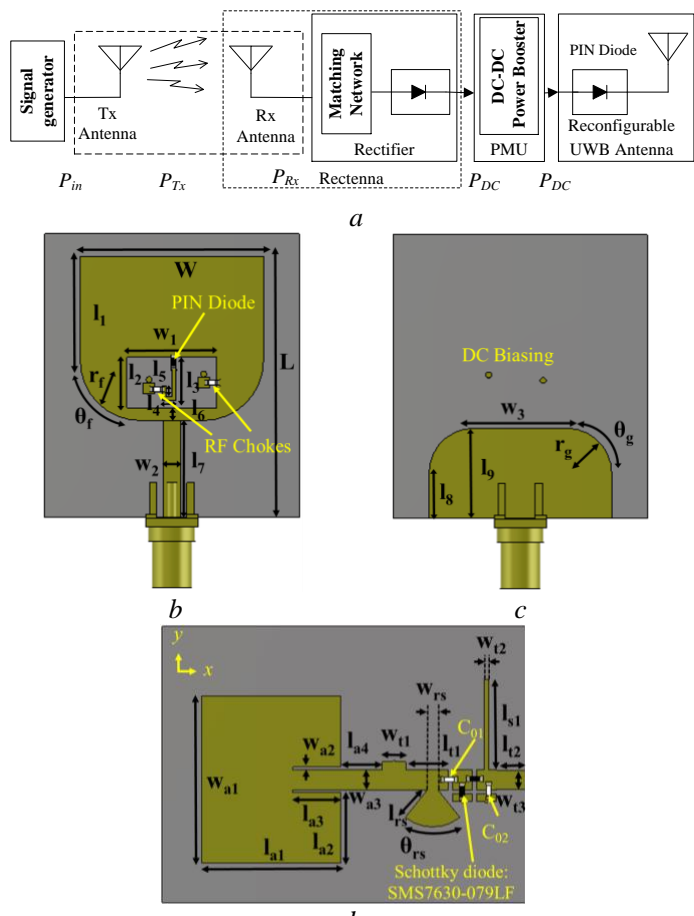

Fig 1. (a). Schematic diagram of the operation principle of the dynamically reconfigurable UWB antenna. Proposed UWB monopole antenna: (b) front view, (c) back view and (d) rectenna module consisting of a microstrip patch antenna connected to a rectifier (voltage doubler). 
Table 1 Schematic Dimensions

\begin{tabular}{lllllll}
\hline \hline \multicolumn{7}{c}{ UWB Antenna } \\
\hline Parameter & $\mathrm{W}$ & $\mathrm{L}$ & $\mathrm{l}_{1}$ & $\mathrm{l}_{2}$ & $\mathrm{l}_{3}$ & $1_{4}$ \\
Value $(\mathrm{mm})$ & 24.5 & 35.0 & 14.0 & 6.75 & 5.74 & 1.5 \\
\hline Parameter & $1_{5}$ & $1_{6}$ & $1_{7}$ & $\mathrm{~L}_{8}$ & $\mathrm{~L}_{9}$ & $\mathrm{~W}_{1}$ \\
Value $(\mathrm{mm})$ & 1.4 & 1.71 & 13.0 & 6.10 & 12.1 & 12.0 \\
\hline Parameter & $\mathrm{W}_{2}$ & $\mathrm{~W}_{3}$ & $\mathrm{r}_{\mathrm{f}}$ & $\mathrm{r}_{\mathrm{g}}$ & $\theta_{\mathrm{f}}$ & $\theta_{\mathrm{g}}$ \\
Value $(\mathrm{mm})$ & 2.40 & 12.5 & 8.00 & 6.00 & $90^{\circ}$ & $90^{\circ}$ \\
\hline \multicolumn{7}{c}{ Rectenna } \\
\hline Parameter & $\mathrm{l}_{\mathrm{a} 1}$ & $\mathrm{l}_{\mathrm{a} 2}$ & $\mathrm{l}_{\mathrm{a} 3}$ & $\mathrm{l}_{\mathrm{a} 4}$ & $1_{\mathrm{rs}}$ & $1_{\mathrm{t} 1}$ \\
Value $(\mathrm{mm})$ & 17.6 & 9.0 & 6.1 & 5.23 & 4.50 & 5.4 \\
\hline Parameter & $1_{\mathrm{t} 2}$ & $1_{\mathrm{s} 1}$ & $\mathrm{w}_{\mathrm{a} 1}$ & $\mathrm{w}_{\mathrm{a} 2}$ & $\mathrm{~W}_{\mathrm{a} 3}$ & $\mathrm{~W}_{\mathrm{t} 1}$ \\
Value mm) & 4.0 & 11.4 & 21.2 & 0.3 & 2.5 & 3.00 \\
\hline Parameter & $\mathrm{W}_{\mathrm{t} 2}$ & $\mathrm{w}_{\mathrm{t} 3}$ & $\mathrm{~W}_{\mathrm{rs}}$ & $\theta_{\mathrm{rs}}$ \\
Value mm) & 0.6 & 2.40 & 1.32 & $35^{\circ}$ & & \\
\hline \hline
\end{tabular}

which may be considered slow for some applications [11]. PIN diodes or varactors have appeared to be a faster and a more compact alternative to RF-MEMS. The switching time of a PIN diode is in the range of $1-100$ nsec. Moreover, the biasing voltage for the RF-MEMS and varactors is very high $(10-100 \mathrm{~V})$ as compared to PIN diodes $(0.3-0.9 \mathrm{~V})$. Biasing voltage is more critical for the required dynamical actuation presented in this work therefore a PIN diode is used as a switch.

Recently, there has been significant research effort towards wireless power transfer (WPT) applications. More often than not, the harvested power is insufficient to support autonomous operation. However, the rectified RF signal can be utilized as an enabling voltage in order to control an active DC-to-DC power booster to supply in turn the required power. For increasing the sensitivity, which means effective sensing of a low power RF signal, it is necessary to develop a highefficiency rectenna (antenna + rectifier) for a wide dynamic range of the available power levels. During the past decade considerable research effort has focused on high-efficiency rectifiers for both low power, [12-15] and high power [16,17] $\mathrm{RF}$ energy rectification. Since the rectifier is non-linearly dependent on the terminating load resistance [16], a power management unit (PMU) is added in order to provide the optimum termination load for the rectifier. Some of the power management units, presented in the literature, aim to effectively store the harvested energy in a rechargeable battery $[18,19]$.

In the proposed dynamically reconfigurable UWB antenna shown schematically in Fig. 1(a), the associated rectenna uses the rectified RF energy to drive the DC-to-DC power booster, since through an enabling voltage the output voltage from the booster is applied to the PIN diode, setting it in "ON" state and resulting in the notch creation. The proposed dynamically reconfigurable UWB antenna shown in Figs. 1(b) and 1(c) is electrically connected to the rectennabooster system. The rectenna that operates at $5.6 \mathrm{GHz}$ consists of a patch antenna connected to a rectifier, as shown in Fig. 1(d). This is subsequently cascaded with a charge pump IC that operates as a DC-to-DC power booster. The combined rectenna-booster system implements the RF triggered PMU from which the PIN diode is biased to reconfigure the UWB antenna dynamically. Both the UWB antenna and the rectenna are fabricated using microstrip technology

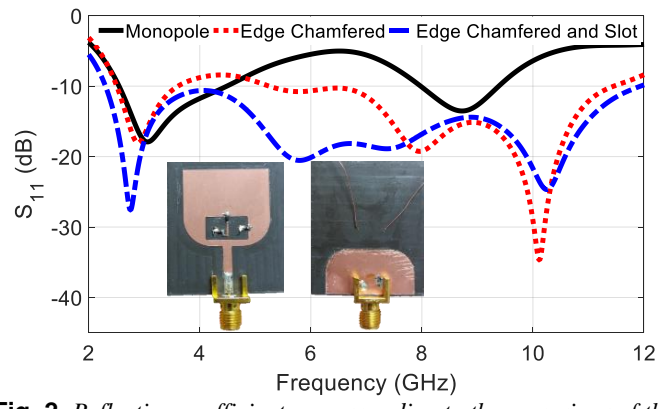

Fig. 2. Reflection coefficient corresponding to three versions of the initial design stage of the proposed UWB antenna without a notchband.

\section{UWB Antenna With Reconfigurable Band- Notch}

The geometry of the UWB monopole antenna with a rectangular slot is shown in Figs 1(b) and 1(c). The UWB antenna was fabricated on a $0.787 \mathrm{~mm}$ thick Rogers RT/duroid 5880 substrate with relative permittivity $\varepsilon_{\mathrm{r}}=2.2$ and loss tangent $\tan \delta=0.0009$, and overall board dimensions of $35(\mathrm{~L}) \times 24.5(\mathrm{~W}) \mathrm{mm}^{2}$.

The rectangular monopole was fed by a $50 \Omega$ characteristic impedance microstrip line, $2.4 \mathrm{~mm}$ wide, and $13 \mathrm{~mm}$ long. As depicted in Fig. 1, the SMA connector was included in the simulation model to improve the agreement between the simulated results and the measurements on the fabricated prototype antenna. Both the radiating patch and the $\mathrm{RF}$ ground plane were chamfered at the bottom and top edges respectively. These chamfered edges produce a smooth transition from the microstrip line guided modes to the radiated ones and they contribute towards the matching improvement over the UWB band [3,4]. The improvement can be verified in Fig. 2 where the effect of the chamfered corners is presented with the red dotted line.

The original model used typical rectangular patches with 90-degree corners for both the monopole radiator, and the ground plane (black solid line). A rectangular slot on the radiating monopole also contributes towards achieving even better impedance matching over the entire UWB frequency range. Fig. 2 displays the effect on the impedance matching of the designed UWB antenna when the corners are rounded and when a rectangular slot is added to the monopole radiator. The comparison of $\left|S_{11}\right|$ is shown for the three different versions of the initial design stage of the proposed UWB antenna. It can be observed that the combination of the rectangular slot with the rounded edges improves the impedance matching significantly. More importantly, the space created by the rectangular slot can be used to accommodate a stub that is subsequently used to create a band-notch response. The fabricated prototype is depicted as inset in Fig. 2.

The J-shaped stub is added inside the created rectangular slot, as shown in Fig. 1(b) and can be clearly recognized in Fig. 3. The stub can create a bandstop filter response (band-notch) in the frequency range of 5-6 GHz, where a number of narrowband applications exist: HIPERLAN/2 $(5.470-5.725 \mathrm{GHz})$ and $5 \mathrm{GHz}$ IEEE $802.11 \mathrm{a} / \mathrm{h} / \mathrm{j} / \mathrm{n}$ WLAN $(5.15-5.35 \mathrm{GHz}, 5.25-5.35 \mathrm{GHz}, 5.47-$ 


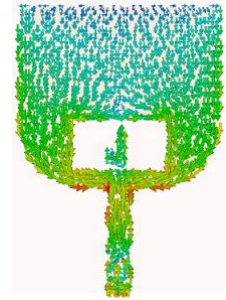

$a$

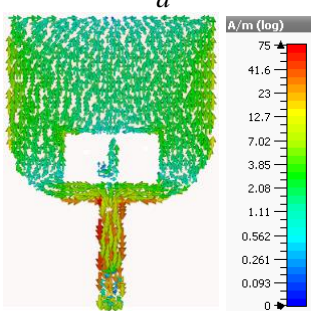

$c$

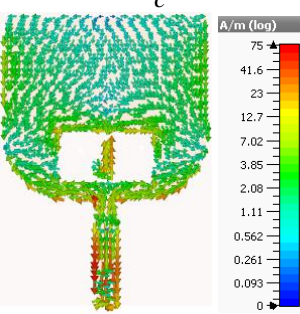

$e$

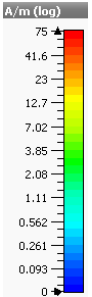

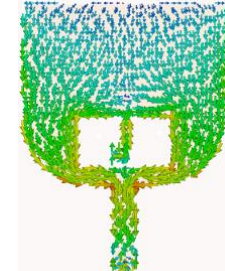

$b$

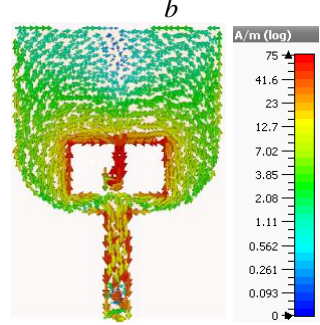

$d$

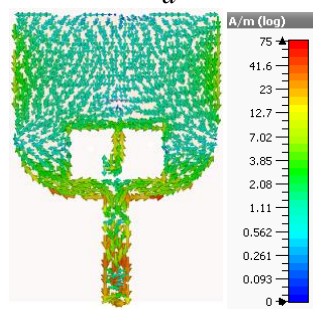

$f$

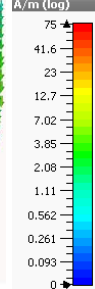

Fig. 3. Surface current distributions at different frequencies. (a) 4 $\mathrm{GHz}$ "OFF", (b) $4 \mathrm{GHz}$ "ON", (c) $5.6 \mathrm{GHz}$ "OFF", (d) $5.6 \mathrm{GHz}$ "ON", (e) 8 GHz "OFF" and $(f) 8 \mathrm{GHz}$ "ON".

5.725 GHz and 5.725-5.825 GHz). The purpose is to eliminate the potentially interfering signal which can be considered as noise for the UWB communications system, and consequently improve the received SNR of the UWB receiver [5]. The bandstop filter characteristic can be dynamically added to the conventional UWB antenna, in the presence of an interferer signal higher than $-10 \mathrm{dBm}$. The detailed simulation model of the dynamically reconfigurable UWB antenna is illustrated in Fig. 1, and the optimized dimensions of the fabricated antenna are summarized in Table 1. In order to accommodate the addition of a switch to implement the dynamic reconfigurability, a gap with a length of $1.2 \mathrm{~mm}$ is created along the stub. To achieve electronic switching, a silicon PIN diode by Skyworks (model SMP1345-079LF) was used, which is specifically suitable for WLAN applications. Simulations were carried out with the CST Microwave Studio and Design Studio co-simulations with PIN diodes' s-parameters (.s2p) files provided by the Skyworks [20] for different forward and reverse biasing conditions.

For the biasing network, small square pads of $1 \times 1$ $\mathrm{mm}^{2}$ are introduced to connect to DC lines via chip inductors $(82 \mathrm{nH})$. These inductors were used as RF chokes to reduce the leakage of RF energy. The DC lines are connected to the biasing circuit on the backside of the antenna through vias to prevent the DC wires from perturbing the radiation performance of the antenna. The biasing DC voltage is
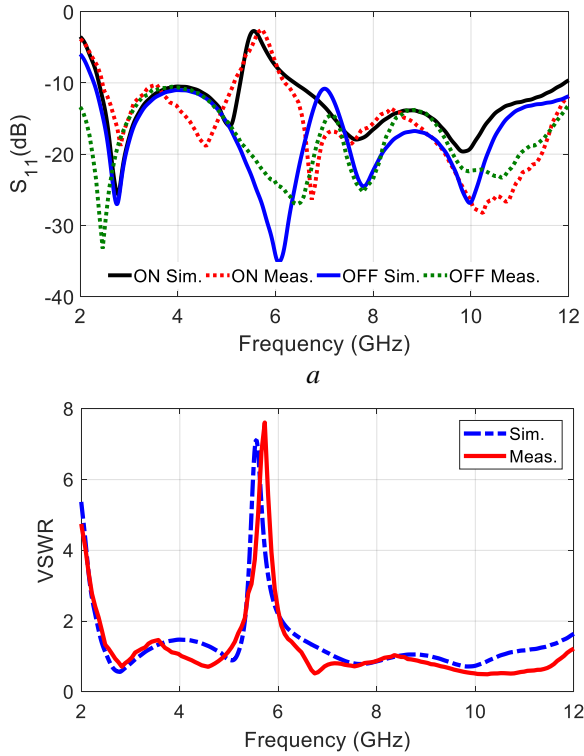

$b$

Fig. 4. Simulated and measured (a) $\left|S_{11}\right|$ of the reconfigurable UWB antenna when the diode is "OFF" and the diode is "ON" and (b) VSWR when the diode is "ON".

provided from the output of the DC-to-DC power booster that is subsequently discussed in Section 4 . The square pads and the DC wires can be seen in Figs 1(b) and 1(c), and also in the photograph of the fabricated reconfigurable band-notch UWB antenna in the inset of Fig. 2. Fig. 3 illustrates the simulated current distributions at different frequencies. It can be seen that the surface current distributions for both "OFF" and "ON" states are similar for every frequency except at the $5.6 \mathrm{GHz}$ for which the electrical length of the J-shaped stub is approximately $\lambda / 4$ for the central band-notch frequency $(5.6 \mathrm{GHz})$. At this particular frequency, the surface current is concentrated mainly along the stub and along the slot's edges (which are parallel to the stub's main length), having opposite directions. As a result, the radiating effect at that frequency is suppressed, the $\left|S_{11}\right|$ presents a notch, and the measured gain is significantly decreased.

The center frequency and the peak of the notch band is controlled by the geometric characteristics of the stub (length, width and position). The stub parameters can be modified to demonstrate a practical implementation of the presented antenna concept when it is required to reject signals from the $5.0 \mathrm{GHz}$ IEEE 802.11y HIPERLAN/2 band (5.470$5.725 \mathrm{GHz}$ ) and the $5 \mathrm{GHz}$ IEEE $802.11 \mathrm{a} / \mathrm{h} / \mathrm{j} / \mathrm{n}$ WLAN band (5.15-5.35 GHz, 5.25-5.35 GHz, 5.47-5.725 GHz and $5.725-5.825 \mathrm{GHz}$ ). To estimate the required stub length for defined specifications which is independent of the substrate dielectric constant, the following piece-wise analytical expression for the stub length $\left(L_{s t b}\right)$ was derived, by curve fitting the full-wave simulation results:

$$
L_{s t b}=-4.852 f_{0}^{3}+77.97 f_{0}^{2}-421.2 f_{0}+774.1 \text { (1) }
$$

Where $L_{s t b}$ is the stub length in $\mathrm{mm}$ and $f_{0}$ is the notch's central frequency in $\mathrm{GHz}$. In order to reject interference caused by IEEE $802.11 \mathrm{j}(5.47-5.725 \mathrm{GHz})$ systems, the initial stub length was estimated, using (1), for the central 

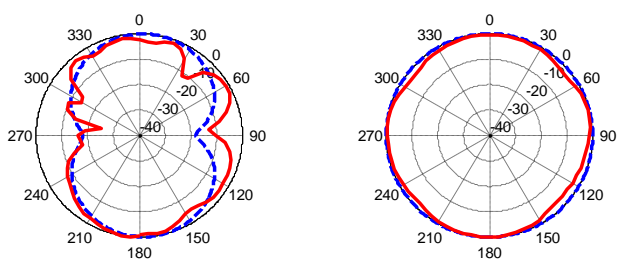

4 GHz $x$-z plane
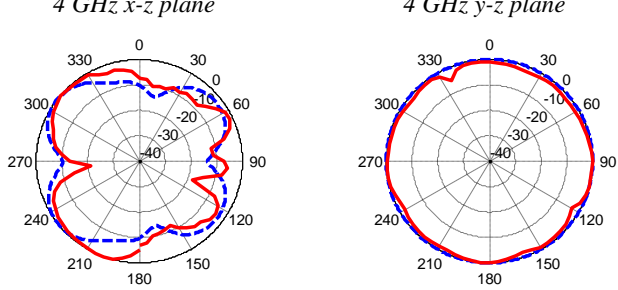

$8 \mathrm{GHz} x$-z plane

$$
\text { - - - Sim. }
$$

$8 \mathrm{GHz}$ y-z plane Meas.

Fig. 5 Simulated and measured radiation patterns in the $E-(x-z)$ and $H-(y-z)$ planes at 4 and $8 \mathrm{GHz}$ frequency with the diode in the "ON" state.

frequency of $5.6 \mathrm{GHz}$. Then the overall stub dimensions (length and width) were fine-tuned using CST full-wave simulations to maximize the peak at the central frequency. The final dimensions for the optimized stub are $L_{s t b}=8.65 \mathrm{~mm}$ and $\mathrm{w}=0.5 \mathrm{~mm}$

\section{UWB Antenna Measurement Results}

The $\left|S_{11}\right|$ comparison between the simulated, and measured results of the proposed UWB antenna with dynamically reconfigurable band-notch are shown in Fig. 4. In the "OFF" state of the diode, a typical UWB antenna response is observed. When the diode is switched to the "ON" state, a frequency notch appears between 5 and $6 \mathrm{GHz}$ with a center frequency of $5.6 \mathrm{GHz}$. Fig. 4b. depicts the simulated and measured VSWR when the dynamically reconfigurable band-notch is created. The S-parameter measurements were taken using an Agilent E8363B vector network analyzer (VNA) and good agreement is observed between the simulated and measured results. The diode can be turned " $\mathrm{ON}$ " in the presence of an RF interfering signal as low as $-10 \mathrm{dBm}$ sensed and rectified by the associated rectenna, as is subsequently demonstrated in Section 5 . The radiation pattern measurements were taken in an anechoic chamber at the Research Institute for Microwave and Millimeter-wave Studies (RIMMS), co-owned by the National University of Sciences and Technology (NUST). The antenna was placed on a rotating platform and gain patterns were measured at discrete frequency points. The gain of the antenna was measured using the substitution method in which a standard rectangular horn antenna of known gain was used.

The measured and the simulated far field radiation patterns at 4 and $8 \mathrm{GHz}$ are shown in Fig. 5 and Fig. 6 when the diode is in the "ON" and "OFF" states, respectively. As expected from the antenna geometry, the E-plane (x-z plane) patterns are basically monopole-like in all cases, while the $\mathrm{H}$ plane (y-z plane) patterns are almost omni-directional. Fig. 7 provides the antenna peak realized gain values versus the
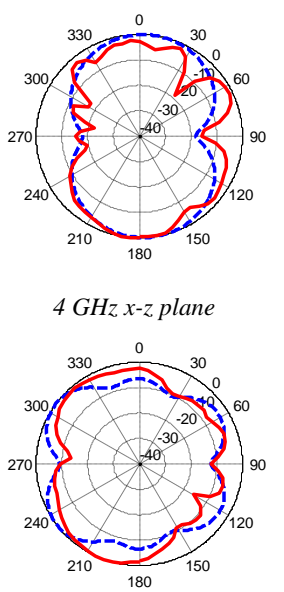

$8 \mathrm{GHz} x$-z plane

$$
\text { -ー--Sim. }
$$

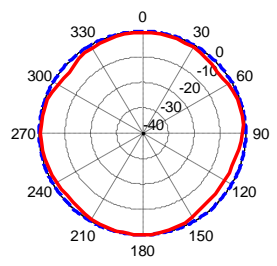

$4 \mathrm{GHz} y$-z plane

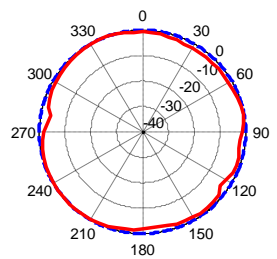

8 GHz y-z plane Meas.

Fig. 6. Simulated and measured radiation patterns in the $E-(x-z)$ and $H-(y-z)$ planes at 4 and $8 \mathrm{GHz}$ frequency with the diode in the "OFF" state.

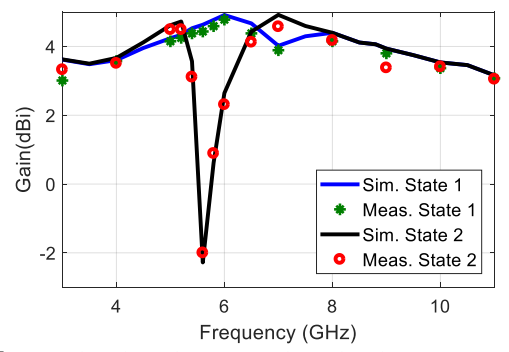

Fig. 7. Simulated and measured realized gain as function of frequency for both "ON" and "OFF" states.

operation frequency. It is observed that the simulated and measured gain values significantly decrease at the bandnotched frequency of $5.6 \mathrm{GHz}$ while they remain mostly unchanged everywhere else.

\section{RF Triggered Power Management Unit}

For the dynamic biasing of the PIN diode an RF scavenging system is needed. Since the required power for the biasing for the PIN diode is $9 \mathrm{~mW}(9.54 \mathrm{dBm})$, which is higher than the usually available RF power, an active RFtriggered power management unit is used. The RF triggered PMU system consists of a rectenna to convert a $5.6 \mathrm{GHz} \mathrm{RF}$ incident signal into a DC voltage and a DC-to-DC power booster that uses the rectified voltage as an enabling signal to provide - in turn - double the biasing DC voltage, to the PIN diode, and thus actuate it from "OFF" to "ON" state to dynamically and effectively reconfigure the UWB antenna.

\subsection{Rectenna}

The $5.6 \mathrm{GHz}$ rectenna consists of a patch antenna and a voltage doubler rectifier as shown in Fig. 1(d). A wellknown topology of an inset microstrip-line-fed rectangular patch antenna [21] with radiation efficiency of $97 \%$ and realized gain of $7.6 \mathrm{dBi}$ is used. Fig. 8 shows the simulated 


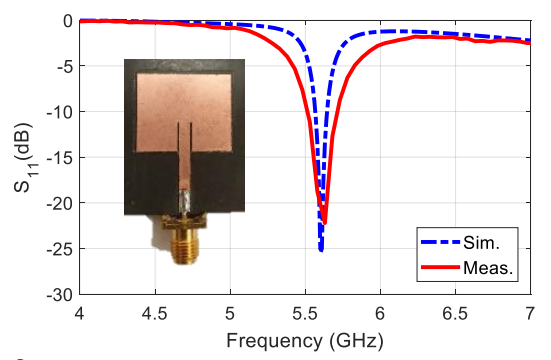

Fig. 8. Simulated and measured reflection coefficient comparison of the patch antenna. The fabricated prototype of the antenna is shown in the inset photograph.

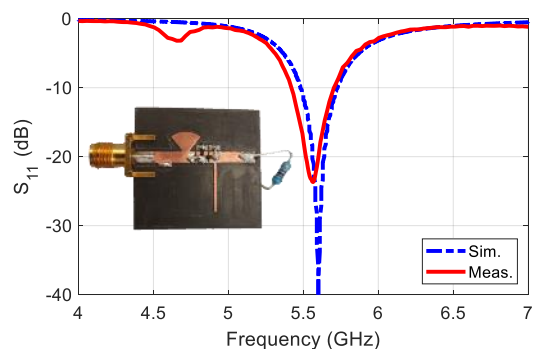

Fig. 9. Simulated and measured reflection coefficient comparison of the rectifier. The fabricated prototype of the rectifier is shown in the inset photograph.

and measured reflection coefficient of the antenna, while the inset shows a photograph of the prototype fabricated independently to test the antenna's performance before it was directly connected to the rectifier to form the rectenna. Rectifiers operating at $5.6 \mathrm{GHz}$ are not very common in the literature, since rectifiers are mostly used for the UHF and ISM bands [22]. As every other rectifier, at any frequency, it is non-linearly dependent on the input power and the termination load. When any of these quantities vary, as is the case for the cascaded DC-to-DC boost converter that has input impedance which depends on its biasing conditions, the design of a high efficiency rectifier becomes a challenging task. To maintain the cost of the rectifier low and the RF-toDC efficiency high, the voltage doubler topology [23] was chosen. The desired characteristics of the designed rectifier include: good impedance matching for the entire input power range, low complexity, low cost and the highest possible RFto-DC efficiency for a wide range of input RF power levels ($25 \mathrm{dBm}$ to $+5 \mathrm{dBm})$. Keysight - Advanced Design System (ADS) was used to first design the rectifier and the vendor's ADS library was used for the electronic component placement to ensure realistic mimicking of the implemented hardware. A Rogers RT/duroid 5880 substrate was used with $\varepsilon_{\mathrm{r}}=2.2, \tan \delta=0.0009$ and substrate thickness $0.787 \mathrm{~mm}$. In the simulations, large scale signal analysis was used to analyze the behavior of the rectifier topology. It is wellknown, that the rectifier has a non-linear response to the input RF signal. Therefore, a harmonic balance simulation was used in ADS, where the fundamental frequency was set to 5.6 $\mathrm{GHz}$ and the order number was set to 5 . A power sweep from $-40 \mathrm{dBm}$ to $+10 \mathrm{dBm}$ was applied in the simulation. The RFto-DC efficiency was optimized for a termination load of 5.1 $\mathrm{K} \Omega$. The fabricated stand-alone rectifier is presented in the inset of Fig. 9, and the optimized set of parameters for the

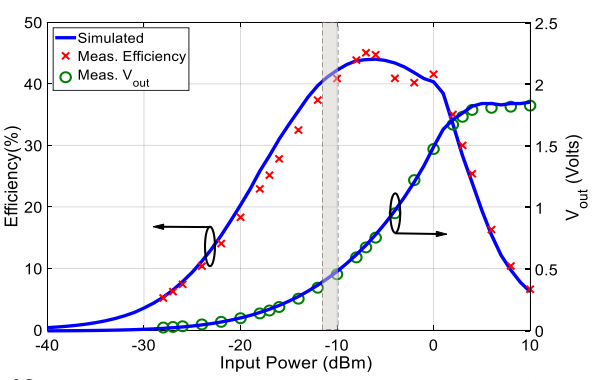

Fig. 10. Simulated and measured rectenna output voltage and rectifier efficiency versus input power at $5.6 \mathrm{GHz}$ across the $5.1 \mathrm{k} \Omega$ load resistance.

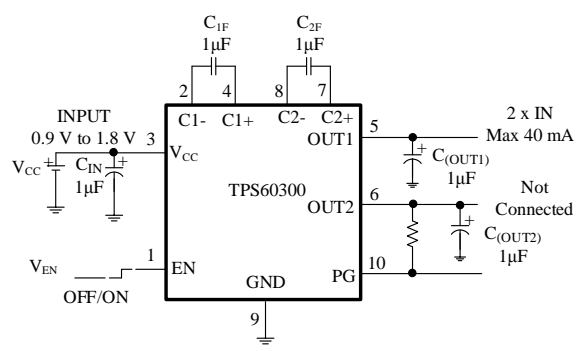

Fig. 11. Schematic of the active DC-to-DC power booster designed using the charge pump IC TPS60300 by Texas Instruments.

fabricated prototype is listed in Table 1. A multi-variable optimization was performed with two simultaneous objectives: a) $50 \Omega$ matching at the input terminal of the rectifier (Eq. (2)) and, b) high RF-to-DC efficiency at the required power range (Eq. (3)).

$$
\begin{gathered}
\Gamma=\frac{Z_{\text {in }}-50}{Z_{\text {in }}+50} \\
\eta=\frac{P_{\text {out }}}{P_{\text {in }}}=\frac{V_{d c}^{2} / R_{L}}{P_{\text {in }}}
\end{gathered}
$$

Here, $Z_{\text {in }}$ is the input impedance at the rectifier input terminal, $P_{\text {in }}$ and $P_{\text {out }}$ are the RF input, and DC output power levels, respectively, and $V_{d c}$ is the voltage across the load resistor $R_{L}$. Trying to achieve these two goals, it was noted that the bandwidth of the rectifier was too narrow, and as a result it was impossible to maintain the matching for the entire input power range $(-25$ to $+5 \mathrm{dBm})$. Generally, Schottky diodes are wideband devices. What actually limits the use of the rectifier is the bandwidth of the matching network, therefore in order to increase the bandwidth the linear open stubs were replaced with radial stubs. The dimensions of this final design presented in Fig. 9 were the result of a Quasi-Newton algorithm-based multivariable optimization. The geometric parameters of the rectifier along with the rectifier capacitor values were defined as variables.

The optimized values for both $\mathrm{C}_{01}=50 \mathrm{pF}$ and $\mathrm{C}_{02}=$ $150 \mathrm{pF}$ (see Fig. 1(d)). Fig. 9 shows the comparison between the simulated and measured $\left|S_{11}\right|$ while the fabricated prototype is displayed in the inset image. A stand-alone rectifier prototype was first fabricated to test its performance before combining it with the patch antenna. The measured $\left|\mathrm{S}_{11}\right|$ remains below $-10 \mathrm{~dB}$ from 5.45 to $5.70 \mathrm{GHz}(250 \mathrm{MHz}$ 


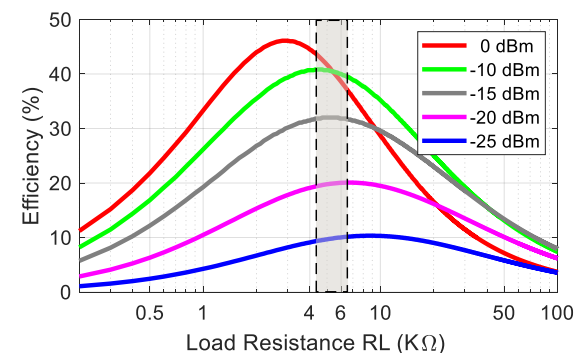

Fig. 12. Simulated rectifier efficiency versus output load for multiple input power levels from -25 to $0 \mathrm{dBm}$ at $5.6 \mathrm{GHz}$.

\begin{tabular}{ccccc}
\multicolumn{5}{c}{ Table 2 Performance Comparison of Different Rectifiers } \\
\hline \hline Ref. & $\begin{array}{c}\text { Freq. } \\
(\mathrm{GHz})\end{array}$ & $\begin{array}{c}P_{\text {in }} \\
(\mathrm{dBm})\end{array}$ & Efficiency & Size $\left(\mathrm{cm}^{2}\right)$ \\
\hline This & $\mathbf{5 . 6}$ & $\mathbf{- 1 0}$ & $\mathbf{4 3 \%}$ & $\mathbf{2 . 0} \times \mathbf{1 . 8}$ \\
work & 5.6 & 16.5 & $52 \%$ & $7.2 \times 4.2$ \\
{$[24]$} & 5.4 & 10 & $51.5 \%$ & $3.5 \times 2.6$ \\
{$[25]$} & 5.8 & $-10,1$ & $20 \%, 39.2 \%$ & $4.5 \times 3.0$ \\
{$[26]$} & 5.8 & 8 & $69.4 \%$ & $4.0 \times 4.0$ \\
{$[27]$} & 5.8 & $-10,0$ & $15 \%, 52.0 \%$ & - \\
{$[28]$} & 5.9 & 0 & $49.2 \%$ & $5 \times 2$ \\
{$[28]$} & 5.8 & & & \\
\hline
\end{tabular}

bandwidth). To measure the efficiency of the rectifier versus the input power, the rectifier was directly connected to a signal generator $(\mathrm{R} \& \mathrm{~S} \circledast \mathrm{SMF} 100 \mathrm{~A})$ while the DC voltage across $R_{L}$ was noted at different input power levels (Pin), at $5.6 \mathrm{GHz}$. An unmodulated sine wave was used to test the efficiency of the rectifier. The efficiency was calculated by changing the power level of the signal generator from, -40 $\mathrm{dBm}$ to $+10 \mathrm{dBm}$. The simulated voltage across the termination load $\left(R_{L}=5.1 \mathrm{k} \Omega\right)$ is compared with the measurements in Fig. 10. The measured efficiency of the rectifier was calculated using Eq. (3) at the corresponding input power levels, and it was compared to the simulated predictions as shown in Fig. 10. The efficiency of the rectifier is approximately $20 \%$ at $-20 \mathrm{dBm}$ and increases to $44.5 \%$ at $5 \mathrm{dBm}$. Since the resulting rectified voltage and DC power were not sufficient to bias the used Schottky diode, an active DC-DC booster was needed. The rectifier has been tested using a single tone signal at $5.6 \mathrm{GHz}$ to ensure fair comparison with the referenced rectifier designs summarized in Table 2. It can be observed that the proposed rectifier has generally high efficiency at low input power (43\% at $-10 \mathrm{dBm})$ and the most compact size compared with other recently reported designs.

\subsection{Active DC-to-DC Power Booster}

According to the PIN diode's datasheet (Skyworks SMP1345) [20], around $0.89 \mathrm{~V}$ and $10 \mathrm{~mA}$ current are needed, in order to switch the diode from the "OFF" to the "ON" state. In realistic scenarios, the available RF signals do not have sufficient power to directly actuate in real time the PIN diode. In such a scenario the PIN diode should be fed directly from the harvested DC power, derived at the rectifier's output terminal. To overcome this problem, an active DC-to-DC power booster is used to provide the required $\mathrm{DC}$ power for the effective biasing of the PIN diode. The proposed boost converter converts the DC power level at the expense of DC

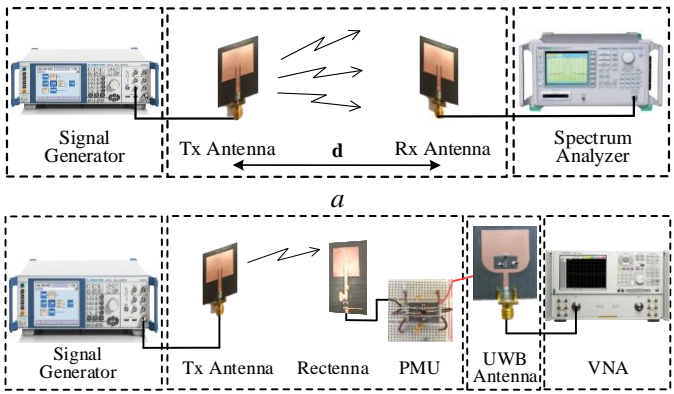

Fig. 13. Measurement setup for the rectenna. (a) Step 1 to define the input RF power in the rectifier, (b) Step 2 to calculate the rectified DC power. Rectenna and DC-to-DC boost converter measurement with signal generator.

biasing voltage $\mathrm{V}_{\mathrm{CC}}$ between 0.9 and $1.8 \mathrm{~V}$ is needed for the active booster's normal operation. A charge pump IC (model TPS60300 from Texas Instruments) [30] is used to design the DC-to-DC converter where the rectified voltage from the rectifier's output terminal is used as the input trigger signal at the EN terminal in order to enable the IC. When a voltage $V_{\text {EN }}$ is high enough to be used as an enabler, an output voltage ( $\mathrm{V}_{\text {OUT1 }}$ ) that is twice the voltage at $\mathrm{V}_{\mathrm{CC}}$ and up to $40 \mathrm{~mA}$ current is delivered to the output terminal of the IC (OUT1). Five $1-\mu \mathrm{F}$ capacitors were connected in the topology shown in Fig. 11 to implement an efficient DC-to-DC power booster. $\mathrm{C}_{\mathrm{IN}}, \mathrm{C}_{\text {(OUT1) }}$ and $\mathrm{C}_{\text {(OUT2) }}$ are the filter capacitors that bypass any noise or pulse to the ground while $\mathrm{C}_{1 \mathrm{~F}}$ and $\mathrm{C}_{2 \mathrm{~F}}$ are the flying capacitors. It should be clarified that the measured input impedance of the booster (i.e. rectifier's $\mathrm{R}_{\mathrm{L}}$, measured between the EN and GND terminals of the IC) fluctuates between 4205 and $6700 \Omega$ in response of the variation of $V_{C C}$ within the range of $0.0-1.8 \mathrm{~V}$. The $\mathrm{V}_{\mathrm{CC}}$ for the set of experiments was set to $0.9 \mathrm{~V}$, the minimum allowed to ensure minimum power consumption. When the terminal $\mathrm{V}_{\mathrm{EN}}$ is set to "high", the booster enters a DC start-up mode in which the flying capacitor $\mathrm{C}_{\mathrm{OUT1}}$ charges up to a maximum of $\mathrm{V}_{\mathrm{CC}}$, then $\mathrm{V}_{\text {OUT1 }}$ delivers twice the $\mathrm{V}_{\mathrm{CC}}$ with a $40 \mathrm{~mA}$ current. The device is enabled when $V_{\mathrm{EN}}$ crosses the threshold from a logic "low" $\left(<0.5 \times \mathrm{V}_{\mathrm{CC}}\right)$ to a logic "high" $\left(>0.5 \times \mathrm{V}_{\mathrm{CC}}\right)$. The typical start-up time for the proposed active booster model is $\sim 400$ $\mu \mathrm{s}$. Fig. 10 shows that the efficiency of the proposed rectifier for power levels close to its sensitivity $(-11 \mathrm{dBm})$ remains around its maximum value.

\subsection{Power Management Unit}

The efficiency of the rectifier is non-linearly dependent on the load resistance $\mathrm{R}_{\mathrm{L}}$ and the impedance of the boost converter depends on the enabling voltage $\mathrm{V}_{\mathrm{EN}}$. Before cascading the rectifier with the active booster, the effect on the rectifier efficiency when $R_{L}$ changes had to be investigated. An analysis is presented in Fig. 12, in which $R_{L}$ was varied from $100 \Omega$ to $1 \mathrm{M} \Omega$ and the simulated efficiency is plotted for multiple input power levels. The results indicate that within the range of $4205-6700 \Omega$, which is the actual range for the measured $\mathrm{R}_{\mathrm{L}}$ values (i.e. the input impedance of the DC-to-DC power booster), the rectifier operates within its maximum efficiency region. This ensures that the RF triggered PMU successfully operates at considerably varying 


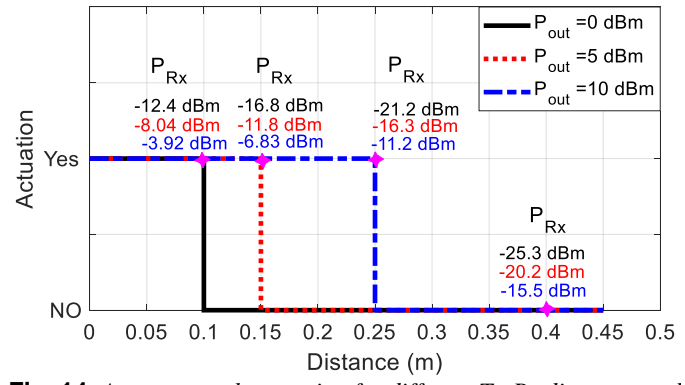

Fig. 14. Antenna notch actuation for different $T x$-Rx distances and different signal generator output power (Pout) level. $P_{R x}$ indicates the power at the input of the rectifier at different distances, as it was measured with a spectrum analyzer.

$\mathrm{R}_{\mathrm{L}}$ values for a wide range of input power levels, despite the rectifier's non-linear dependence on the output load resistance $\mathrm{R}_{\mathrm{L}}$ as shown in equation (3). The non-linear dependence of the rectifier's RF-to-DC efficiency with respect to the termination load prevents the direct connection of the rectifier with the PIN diode and makes the intermediate DC-to-DC power booster necessary despite the inevitable, total efficiency, degradation.

\section{Implementation and Testing}

The UWB antenna and the rectenna were fabricated on a Rogers RT/duroid 5880 substrate using an LPKF ProtoMat H100 milling machine. The PIN diodes (Skyworks SMP1345-079LF), and RF choke inductors (Coilcraft series 0402CS $-82 \mathrm{nH}$ ) were soldered on the top layer of the UWB antenna, while the Schottky diodes (Skyworks SMS7630079LF) and SMD capacitors (Murata series GJM03) were mounted on the rectenna module. Finally, the charge pump IC (TI model TPS60300) with five capacitors $(1 \mu \mathrm{F})$ was implemented on a breadboard. Wires were used to connect the rectifier output terminal to the DC-to-DC power booster. Finally, the OUT1 terminal of the converter was connected to the biasing pads on the back side of the UWB antenna using bond wires.

The measurement setup was implemented as shown in Figs 13(a) and 13(b). In Step 1 the received RF power $\left(P_{R X}\right)$ was measured using a spectrum analyzer, and in Step 2 the rectified available power at the same distance $d$, on the terminating load resistance was measured using a digital multi-meter (DMM). The patch antenna presented in Fig. 8 was connected to the signal generator to be used as an RF power transmitter and the rectenna was used at the receiving end. The generated power from the signal generator is labeled in Fig. 14 as Pout and the received power at the input of the rectifier is labeled as $\mathrm{P}_{\mathrm{RX}}$. The DC-to-DC power booster circuit, was connected to the output terminal of the rectifier in order to use the rectified voltage as an enabling voltage. During the measurement process, it was observed that when the output voltage of the rectifier (which is also the driving voltage $\mathrm{V}_{\mathrm{EN}}$ of the DC-to-DC power booster) went above 0.43 $\mathrm{V}$, the power booster successfully actuated the PIN diode that was used on the UWB antenna. When $\mathrm{V}_{\mathrm{EN}}$ dropped below the threshold, the output voltage of the charge pump IC was disabled and the PIN diode returned to the "OFF" state in real time.
In order to verify the successful implementation and the performance of the proposed UWB antenna with the dynamically reconfigurable notch-band, S-parameter measurements of the UWB antenna (Fig. 2) were taken in both the absence and presence of the RF triggering signal. In the laboratory setup presented in Fig. 13(b), RF signals of multiple power levels were generated by the signal generator that was connected to a patch $T_{x}$ antenna (identical to the one in Fig. 8 inset) acting as a transmitter. The transmitted, unmodulated, $5.6 \mathrm{GHz}$ signal, was received and rectified from the rectenna. The rectified RF signal was used as enabling voltage for the cascaded active booster, to make its DC power supply available at its terminal OUT1, in order to dynamically actuate the PIN diode and thus reconfigure the UWB antenna. The output voltage of the boost converter was measured with a DMM. Testing was repeated for three different distances between the transmitter and the receiver antennas, and three different power levels and the measurement results are summarized in Fig. 14. The actuation of the PIN diode was successful when the received power $P_{R X}$ at the input of the rectifier was higher than -10 $\mathrm{dBm}$.

Dynamic reconfiguration of the UWB antenna was observed at distances between the transmitter and receiver antennas of $0.5,0.15$, and $0.25 \mathrm{~m}$ when the signal generator power (Pout) was set to 0,5 and $10 \mathrm{dBm}$, respectively. According to FCC the maximum transmitted power of Unlicensed National Information Infrastructure (U-NII) Worldwide / U-NII-2C / U-NII-2-Extended / U-NII-2e $(5.470-5.725 \mathrm{GHz})$ at $5.6 \mathrm{GHz}$ can be as high as $+23 \mathrm{dBm}(20$ times higher than the maximum used $10 \mathrm{dBm}$ ) and if used the maximum distance can be multiplied accordingly. During the testing, it was observed that a metallic screen, placed between the transmitter and the receiver antennas, effectively blocking the RF trigger signal, switched the diode from the "ON" to the "OFF" state practically instantly, demonstrating the elimination of the RF triggered dynamically reconfigurable frequency notch of the proposed UWB antenna in real time.

\section{Conclusion}

A UWB monopole antenna with a dynamically reconfigurable notch-band at $5.6 \mathrm{GHz}$ has been implemented and presented. This includes an associated rectenna with a customized DC-to-DC power booster that enables the dynamic creation of the notch in the presence of an external $\mathrm{RF}$ signal equal or stronger than $-11 \mathrm{dBm}$. The UWB monopole has a rectangular slot, which hosts a J-shaped stub, and is connected to the radiator through a single PIN diode. With the diode in the "OFF" state the antenna operates as a conventional UWB radiator. When the diode is set to the "ON" state the J-shaped stub is electrically connected to the radiator, which causes the creation of a notch-band with a bandstop filter effect. The notch creation causes a significant reduction in the gain and improves the received SNR by rejecting the relatively strong interfering signal at $5.6 \mathrm{GHz}$. The interfering signal is detected and received from a rectenna that consists of a high gain $(7.6 \mathrm{dBi})$ patch antenna and a voltage doubler. The rectified $5.6 \mathrm{GHz}$ input signal from the rectenna is used as an enabling voltage to a cascaded active DC-to-DC power booster with an output terminal connected to the biasing pads of the UWB antenna's PIN diode. Using its $\mathrm{V}_{\mathrm{CC}}$ biasing voltage, the booster provides the PIN diode with sufficient 
power to switch to the "ON" state. As a result, the detection of a $-11 \mathrm{dBm}, 5.6 \mathrm{GHz}$ signal, leads to the dynamic creation of a notch-band in the reflection coefficient plot which leads to the effective cancellation of the interferer. When the received interferer signal is eliminated, the frequency notch immediately disappears, practically in real time, and the UWB antenna returns to a conventional UWB radiator mode. The switching can be repeated as many times as the $5.6 \mathrm{GHz}$ interferer appears or disappears, verifying a dynamic response and the dynamic reconfigurability of the proposed UWB antenna, triggered only from external interfering or controlling signals.

\section{Acknowledgments}

The authors would like to thank Dr. Stavros Iezekiel and Dr. Andreas Perentos from University of Cyprus, Nicosia, for providing the equipment for some of the measurements.

\section{References}

[1] I. Y. Immoreev, "Practical applications of UWB technology," IEEE Aerospace and Electronic Systems Magazine, vol. 25, no. 2 , pp. $36-42$, Feb. 2010

[2] G. Adamiuk, T. Zwick, and W. Wiesbeck, "UWB Antennas for Communication Systems," Proceedings of the IEEE, vol. 100, no. 7, pp. 2308-2321, Jul. 2012.

[3] M. C. Tang, H. Wang, T. Deng, and R. W. Ziolkowski, "Compact Planar Ultrawideband Antennas With Continuously Tunable, Independent Band-Notched Filters," IEEE Transactions on Antennas and Propagation, vol. 64, no. 8, pp. 3292-3301, Aug. 2016.

[4] S. M. Abbas, Y. Ranga, A. K. Verma, and K. P. Esselle, "A Simple Ultra Wideband Printed Monopole Antenna With High Band Rejection and Wide Radiation Patterns," IEEE Transactions on Antennas and Propagation, vol. 62, no. 9, pp. 4816-4820, Sept. 2014.

[5] S. Nikolaou, N. D. Kingsley, G. E. Ponchak, J. Papapolymerou, and M. M. Tentzeris, "UWB Elliptical Monopoles With a Reconfigurable Band Notch Using MEMS Switches Actuated Without Bias Lines," IEEE Transactions on Antennas and Propagation, vol. 57, no. 8, pp. 2242-2251, Aug. 2009.

[6] S. Nikolaou, M. Davidović, M. Nikolić, and P. Vryonides, "Triple notch UWB antenna controlled by three types of resonators," in 2011 IEEE International Symposium on Antennas and Propagation (APSURSI), Jul. 2011, pp. 1478 1481.

[7] H. Oraizi and N. V. Shahmirzadi, "Frequency-and timedomain analysis of a novel UWB reconfigurable microstrip slot antenna with switchable notched bands," IET Microwaves, Antennas \& Propagation, vol. 11, no. 8, pp. 1127-1132, Feb. 2017.

[8] O. A. Safia, M. Nedil, L. Talbi, and K. Hettak, "Coplanar waveguide-fed rose-curve shape UWB monopole antenna with dual-notch characteristics," IET Microwaves, Antennas \& Propagation, vol. 12, no. 7, pp. 1112-1119, Jan. 2018.

[9] S. Saxena, B. K. Kanaujia, S. Dwari, S. Kumar, and R. Tiwari, "Compact ultra-wideband microstrip antenna with dual polarisation/multi-notch characteristics," IET Microwaves, Antennas \& Propagation, Mar. 2018

[10] S. Nikolaou et al., "Pattern and frequency reconfigurable annular slot antenna using PIN diodes," IEEE Transactions on Antennas and Propagation, vol. 54, no. 2, pp. 439-448, Feb. 2006.

[11] C. G. Christodoulou, Y. Tawk, S. A. Lane, and S. R. Erwin, "Reconfigurable Antennas for Wireless and Space
Applications," Proceedings of the IEEE, vol. 100, no. 7, pp. 2250-2261, Jul. 2012

[12] A. Georgiadis, G. V. Andia, and A. Collado, "Rectenna design and optimization using reciprocity theory and harmonic balance analysis for electromagnetic (EM) energy harvesting," IEEE Antennas and Wireless Propagation Letters, vol. 9, pp. 444-446, May 2010

[13] M. Piñuela, P. D. Mitcheson, and S. Lucyszyn, "Ambient RF Energy Harvesting in Urban and Semi-Urban Environments," IEEE Transactions on Microwave Theory and Techniques, vol. 61, no. 7, pp. 2715-2726, Jul. 2013.

[14] A. Khemar, A. Kacha, H. Takhedmit, and G. Abib, "Design and experiments of a dual-band rectenna for ambient RF energy harvesting in urban environments," IET Microwaves, Antennas \& Propagation, vol. 12, no. 1, pp. 49-55, 2017.

[15] F. Meddour and Z. Dibi, "An efficient small size electromagnetic energy harvesting sensor for low-DC-power applications," IET Microwaves, Antennas \& Propagation, vol. 11, no. 4, pp. 483-489, Oct. 2016.

[16] E. Falkenstein, M. Roberg, and Z. Popovic, "Low-Power Wireless Power Delivery," IEEE Transactions on Microwave Theory and Techniques, vol. 60, no. 7, pp. 2277-2286, Jul. 2012.

[17] P. Ji-Yong, H. Sang-Min, and T. Itoh, "A rectenna design with harmonic-rejecting circular-sector antenna," IEEE Antennas and Wireless Propagation Letters, vol. 3, no. 1, pp. 52-54, Dec. 2004.

[18] A. Costanzo, A. Romani, D. Masotti, N. Arbizzani, and V. Rizzoli, "RF/baseband co-design of switching receivers for multiband microwave energy harvesting," Sensors and Actuators A: Physical, vol. 179, pp. 158-168, Jun. 2012.

[19] D. Masotti, A. Costanzo, P. Francia, M. Filippi, and A Romani, "A load-modulated rectifier for RF micropower harvesting with start-up strategies," IEEE Transactions on Microwave Theory and Techniques, vol. 62, no. 4, pp. 994 1004, Apr. 2014.

[20] S. Solutions. (February). PIN Diodes Available: http://www.skyworksinc.com/Product/486/SMP1345_Series Accessed on: Feb. 2019.

[21] K.-L. Wong, Compact and broadband microstrip antennas. John Wiley \& Sons, 2004.

[22] C. Song, Y. Huang, J. Zhou, and P. Carter, "Recent advances in broadband rectennas for wireless power transfer and ambient RF energy harvesting," in Antennas and Propagation (EUCAP), 2017 11th European Conference on, Mar. 2017, pp. 341-345: IEEE

[23] J. C. Salmon, "Circuit topologies for single-phase voltagedoubler boost rectifiers," IEEE Transactions on Power Electronics, vol. 8, no. 4, pp. 521-529, Oct. 1993.

[24] P. Lu, X.-S. Yang, J.-L. Li, and B.-Z. Wang, "Polarization reconfigurable broadband rectenna with tunable matching network for microwave power transmission," IEEE Trans. Antennas Propag., vol. 64, no. 3, pp. 1136-1141, Mar. 2016.

[25] D. Wang and R. Negra, "Design of a dual-band rectifier for wireless power transmission," in Proc. IEEE Wirel. Power Transf. (WPT), Perugia, Italy, May 2013, pp. 127-130.

[26] M. ur Rehman, W. Ahmad and W. T. Khan, "Highly efficient dual band $2.45 / 5.85 \mathrm{GHz}$ rectifier for RF energy harvesting applications in ISM band," 2017 IEEE Asia Pacific Microwave Conference (APMC), Kuala Lumpar, 2017, pp. 150-153

[27] J. Ou, S. Y. Zheng, A. S. Andrenko, Y. Li and H. Tan, "Novel Time-Domain Schottky Diode Modeling for Microwave Rectifier Designs," in IEEE Transactions on Circuits and Systems I: Regular Papers, vol. 65, no. 4, pp. 1234-1244, April 2018.

[28] M. Kanoun, D. Cordeau, J. Paillot, H. Mnif and M. Loulou, "A 5.9 GHz RF rectifier for wireless power transmission applications," 2017 24th IEEE International Conference on 


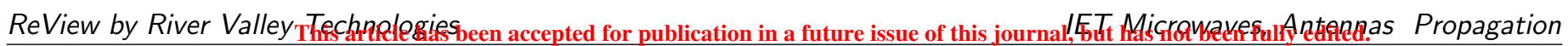
Content may change prior to final publication in an issue of the journal. To cite the paper please use the doi provided on the Digital Library page.

Electronics, Circuits and Systems (ICECS), Batumi, 2017, pp. 385-388.

[29] H. Lee and J. Lee, "Optimization of a 5.8-GHz rectifier considering ripple amplitude and DC-voltage pattern," 2014 IEEE Wireless Power Transfer Conference, Jeju, 2014, pp. 212-215.

[30] T. Instruments. Texas Instruments Charge Pump IC: TPS60301. Available: http://www.ti.com/product/TPS60301 